\title{
Microbial Oxidation of Hydrocarbons. Oxidation of p-Isopropyltoluene by a Pseudomonas sp.
}

\author{
By R. I. LEAVITT \\ Mobil Oil Corporation, Central Research Division, \\ Princeton, New Jersey
}

(Accepted for publication 9 June 1967)

\begin{abstract}
SUMMARY
Whole organisms and soluble extracts of a Pseudomonas sp. were examined for their ability to oxidize suspected intermediates in the oxidation of $p$-isopropyltoluene. A comparison of the relative activities of glucosegrown and $p$-isopropyltoluene-grown bacteria and their extracts indicated that $p$-isopropylbenzyl alcohol, $p$-isopropylbenzaldehyde and $p$-isopropylbenzoic acid are intermediates in the oxidation of the hydrocarbon. $p$-Isopropylbenzoic acid was formed during growth on $p$-isopropyltoluene and this was also shown to be a product of the oxidation of $p$-isopropyltoluene, $p$-isopropylbenzyl alcohol and $p$-isopropylbenzaldehyde by soluble extracts prepared from $p$-isopropyltoluene-grown bacteria. The enzymes which catalyze the oxidation of $p$-isopropyltoluene were repressed by glucose and induced by growth on either $p$-isopropyltoluene or $p$-isopropylbenzoic acid.
\end{abstract}

\section{INTRODUCTION}

In 1957 Dagley \& Patel described the oxidation of $p$-hydroxytoluene by a Pseudomonas sp. and indicated that the route of degradation proceeded via $p$-hydroxylbenzyl alcohol to the aldehyde and then $p$-hydroxybenzoic acid. Such an attack on the methyl group of an aromatic compound was also suggested by the work of Davis \& Raymond (196I). The Nocardia described in their report was incapable of growth on $p$-isopropyltoluene but could convert this compound to $p$-isopropylbenzoic acid while growing at the expense of hexadecane. Yamada, Horiguchi \& Takahashi (1965) described the formation of $p$-isopropylbenzoic acid from $p$-isopropyltoluene by several strains of Pseudomonas. The pathway involved in the oxidation of $p$-isopropyltoluene has never been verified by either induction studies or the use of cell-free extracts, although from the work mentioned it is probable that the methyl group serves as the initial point of enzymic attack. The work reported here was initiated to gain further insight into the mechanism of $p$-isopropyltoluene oxidation by microorganisms.

\section{METHODS}

Chemicals. Terpene-free $p$-isopropyltoluene was purchased from the Matheson Company (East Rutherford, N.J.). p-Isopropyl alcohol, $p$-isopropylbenzaldehyde and $p$-isopropylbenzoic acid were purchased from the Eastman Kodak Company (Rochester, N.Y.). $p$-Isopropylbenzaldehyde was further purified by formation of its bisulfite addition compound which was hydrolysed with dilute base immediately 
prior to its use. $p$-Isopropyltoluene and $p$-isopropylbenzyl alcohol were washed with dilute base prior to their use. Co-factors and 2,3,5-triphenyltetrazolium chloride were purchased from the Sigma Chemical Company (St Louis, Mo.)

Identification of organism. The organism used in this study was a Gram-negative, polarly flagellated rod. It formed a green water-soluble pigment during growth on $p$-isopropyltoluene or glucose. The organism did not grow on glucose or $p$-isopropyltoluene in the absence of oxygen. In accordance with these criteria it was identified as a member of the genus Pseudomonas.

Growth of organism. The pseudomonad was grown in a mineral-salts medium, sterilized by autoclaving for $15 \mathrm{~min}$. at $\mathrm{I}_{5} \mathrm{lb}$./in. ${ }^{2}$, of the following composition (g./1.): $\left(\mathrm{NH}_{4}\right)_{2} \mathrm{SO}_{4}, 2.0 ; \mathrm{MgSO}_{4} .7 \mathrm{H}_{2} \mathrm{O}, 0.2 ; \mathrm{Na}_{2} \mathrm{HPO}_{4}, 3.0 ; \mathrm{KH}_{2} \mathrm{PO}_{4}, 2.0 ; \mathrm{CaCl}_{2}, 0.0 \mathrm{O}$; $\mathrm{Na}_{2} \mathrm{CO}_{3}, 0 . \mathrm{I} ; \mathrm{FeSO}_{4} \cdot 7 \mathrm{H}_{2} \mathrm{O}, 0.005 ; \mathrm{MnSO}_{4}, 0.002$. A seed inoculum for a 31 . fermenter was prepared by inoculating a $250 \mathrm{ml}$. Erlenmeyer flask containing $50 \mathrm{ml}$. mineral salts medium with a loopful (0.0I $\mathrm{ml}$.) of organisms which had been grown and maintained on solidified medium. $p$-Isopropyltoluene $(0.2 \mathrm{ml}$., $174 \mathrm{mg}$.) was added directly to the flask. The hydrocarbons were sterilized by filtration. The flask was shaken at $30^{\circ}$ for $48 \mathrm{hr}$ to yield a population with an extinction of 4.0 when measured at $400 \mathrm{~m} \mu$. All extinction determinations in this study were made with a Spectronic 20 colorimeter (Bausch and Lomb, Rochester, N.Y.). Twenty ml. of this seed inoculum was added to 31 . of mineral-salts medium contained in a 51 . fermenter. This was incubated at $30^{\circ}$ in a New Brunswick fermenter (Model FS-305, New Brunswick Scientific Co., New Brunswick, N.J.) and was continuously agitated by means of an immersed propeller which revolved at a speed of $700 \mathrm{rev} . / \mathrm{min}$. Air was bubbled through the culture at a rate of $400 \mathrm{ml} . / \mathrm{min}$. $p$-Isopropyltoluene (I0.0 ml., $8.6 \mathrm{~g}$.) was added to the culture with the inoculum. After $24 \mathrm{hr}$ the culture was harvested by centrifugation at $6000 \mathrm{~g}$ for $10 \mathrm{~min}$. at $3^{\circ}$. The bacteria were washed with cold distilled water and resuspended to a concentration of $\mathrm{I} g$. wet weight bacteria in $4 \mathrm{ml}$. water. The yield varied from 6 to $\mathrm{I} 2 \mathrm{~g}$. wet wt organisms/1. medium.

Preparation of extracts. Cell-free extracts were prepared by ultrasonic disintegration $\left(20 \mathrm{kc}\right.$. $/ \mathrm{sec}$. for $5 \mathrm{~min}$. at $\left.14^{\circ}\right)$ of suspensions of organisms ( $\cdot \circ \mathrm{g}$. wet wt $/ 4.0 \mathrm{ml}$. water) in a Branson Sonifer Model S-75 (Heat Systems Co., Long Island, N.Y.). The extract was clarified by centrifugation for $30 \mathrm{~min}$. at $34,000 \mathrm{~g}$ at $3^{\circ}$.

Chromatography. The solvent systems utilized for thin-layer chromatography were: A, butanol +ethanol + ammonia $(8+\mathrm{I}+3$ by vol. $)$; $\mathrm{B}$, butanol + acetic acid + water $(6+2+2$ by vol.). Thin-layer chromatograms were sprayed with $0.03 \%(w / v)$ aqueous solution of methyl red buffered with $0.05 \mathrm{M}$-tris $(\mathrm{pH} 7 \cdot 2)$ or with ammoniacal silver nitrate. Pre-coated sheets of silica gel were used for identification of the enzymeproduced intermediates. The sheets were purchased from Distillation Products Industries (Rochester, N.Y.)

Gas-chromatographic analyses were done: A, with a Io $\mathrm{ft} . \times 5 \mathrm{~mm}$. internal diameter stainless steel tube packed with $30 \%(\mathrm{w} / \mathrm{v})$ silicone rubber coated on Diatoport-S-60$80 \mathrm{mesh}$; B, with a $6 \mathrm{ft} . \times 5 \mathrm{~mm}$. internal diameter stainless steel tube packed with $6 \%(\mathrm{w} / \mathrm{v})$ diethylene glycol succinate (Lac 728) on Chromosorb W, 80 mesh. The helium flow rate was $30 \mathrm{ml} . / \mathrm{min}$. and the temperature was maintained at $250^{\circ}$. A thermal conductivity detector system was employed. Acids were detected as their methyl esters. All columns and support materials were purchased from the F and $M$ Scientific Corp., Avondale, Pa. 
Assay methods. Glucose was assayed with glucose oxidase and peroxidase by the method of Bergmeyer \& Bernt (1963). The enzymes were purchased from Calbiochem (Los Angeles, Calif.).

The amount of $p$-isopropylbenzoic acid formed during growth on $p$-isopropyltoluene was determined as follows. Samples were withdrawn from the culture medium and centrifuged to remove the bacteria. The clarified supernatant fluids ( $\mathrm{I} \cdot 0 \mathrm{ml}$.) were acidified with $0 . \mathrm{I} \mathrm{ml}$. $10 \mathrm{~N}-\mathrm{H}_{2} \mathrm{SO}_{4}$ which resulted in the formation of a white precipitate of $p$-isopropylbenzoic acid. A clarified culture of the same density of organisms grown with glucose as the sole carbon source remained clear upon the addition of an equal amount of acid. Since no other product accumulated during growth on $p$-isopropyltoluene, the opacity, measured at $400 \mathrm{~m} \mu$ of, the clatrified supernatant fluid which occurred after the addition of acid was used as a measure of the amount of $p$-isopropylbenzoic acid formed. The quantity of acid formed was determined by comparison with a standard solution and is expressed as $\mu \mathrm{g}$. $/ \mathrm{mg}$. dry wt organisms. The solvent used for the standard solution was the mineral salts medium previously described.

Protein was determined by the method of Itzhaki \& Gill (1964).

The dye 2,3,5-triphenyltetrazolium chloride was used as an electron acceptor in all enzyme assays unless otherwise noted. The reduction of the dye was nil in the absence of either enzyme or cell material or in the presence of boiled extract incubated with substrate. The extinction coefficient of the coloured formazan at $500 \mathrm{~m} \mu$ remained constant from 0 to $55 \%$ absorbancy and proceeded linearly with respect to both increasing time and enzyme or cell concentration. The absorbance $\div 3.64=$ number of $\mu$ moles of substrate oxidized. The assay system contained in I $\circ \mathrm{ml}$.: tris buffer ( $\mathrm{pH} 8.0$ ), $33 \mu$ moles; washed bacteria; substrate, $33 \mu$ moles; and 2,3,5-triphenyltetrazolium chloride, I $\mu$ mole. Tubes were incubated for $20 \mathrm{~min}$. at $25^{\circ}$ and the reaction interrupted by the addition of $3.0 \mathrm{ml}$. of $95 \%$ ethanol. The solutions were clarified by centrifugation and the extinction of the coloured formazan formed was determined at $500 \mathrm{~m} \mu$. This assay was used to obtain the results shown in Tables I-5.

For the induction studies in which $p$-isopropyltoluene was the inducer (Table $\mathrm{I}$ ) organisms were grown for $18 \mathrm{hr}$ in the mineral-salts medium supplemented with a limiting concentration of glucose $(0 \cdot 1 \%)$. Glucose $(0 \cdot 1 \%)$ plus $p$-isopropyltoluene $(0.1 \%)$ were then added to the culture. The culture was shaken at $30^{\circ}$ and subsequent changes in turbidity were followed together with the ability of washed cells, suspended in water, to oxidize $p$-isopropyltoluene, $p$-isopropylbenzyl alcohol and $p$-isopropylbenzaldehyde and with the appearance of $p$-isopropylbenzoic acid in the medium. The first sample $(2 \mathrm{hr}$ ) was taken before glucose exhaustion (corresponding to $2 \mathrm{hr}$ in Fig. I).

For the study in which the oxidative capacities of $p$-isopropyltoluene-grown and $p$-isopropylbenzoate-grown bacteria are described (Table 2), the organisms were harvested after growth ( $18 \mathrm{hr})$ on the carbon source indicated $(0.2 \%)$, resuspended in distilled water and assayed for their oxidative capacities using tetrazolium chloride as an electron acceptor. Tubes were incubated as previously described at $25^{\circ}$ for Io min.

Organisms grown on the surface of solidified mineral medium ( $0.2 \%$ agar) for $17 \mathrm{hr}$ in the presence of possible inducers (Table 3) were suspended in distilled water and assayed for their oxidative capacities as previously described. Solid compounds 
$(0.2 \%)$ were incorporated in the medium. When liquid hydrocarbons or their derivatives were used, the cultures were incubated in atmospheres saturated with their vapours.

For the experiment in which the product formed by incubating $p$-isopropyltoluene with the cell-free extract was characterized, the reaction mixture contained: tris buffer ( $\mathrm{pH} \mathrm{8} \cdot 0$ ), $330 \mu$ moles; substrate, I•0 m-mole; ethanol, $200 \mu$ moles; cysteine, $200 \mu$ moles; extract containing $50 \mathrm{mg}$. protein and distilled water. Total volume, $20 \mathrm{ml}$. The reaction was incubated in air for $18 \mathrm{hr}$, acidified and extracted as described in Methods.

For the experiment in which the product formed by incubating $p$-isopropylbenzyl alcohol and $p$-isopropylbenzaldehyde with the cell-free extract was characterized, the reaction mixture contained: tris buffer ( $\mathrm{pH} 8 \cdot 0$ ), $330 \mu$ moles; substrate, $\mathrm{I} \cdot 0 \mathrm{~m}$-mole; NAD, $20 \mathrm{mg}$.; extract containing $50 \mathrm{mg}$. of protein and distilled water. Total volume, $20 \mathrm{ml}$. The mixtures were incubated under $\mathrm{N}_{2}$ for $3 \mathrm{hr}$, acidified and extracted as previously described.

\section{RESULTS}

\section{Studies with whole organisms}

During growth of the organism on $p$-isopropyltoluene, a compound was formed which could be precipitated from the clarified culture by adding mineral acid to $\mathrm{pH}$ $\mathrm{I} \cdot \mathrm{O}$. This compound was isolated and identified as $p$-isopropylbenzoic acid, as follows. The suspension was extracted with an equal volume of diethyl ether and the ethereal solution was re-extracted with aqueous $\mathrm{N}-\mathrm{NaOH}$. Ether extraction was repeated after acidification of the aqueous solution. The compound was recovered from this ethereal solution by evaporation to dryness, the residue was then dissolved in ethanol and crystallized by adding water. The white crystalline product melted at $1 \mathrm{I} 6-117^{\circ}$ and did not depress the melting point of authentic $p$-isopropylbenzoic acid. Chloroform solutions of the unknown compound and of $p$-isopropylbenzoic acid had identical i.r. spectra. The compound and its methyl ester were chromatographically indistinguishable from $p$-isopropylbenzoic acid and its methyl ester by thin-layer and vapourphase chromatographic techniques, respectively.

The formation of $p$-isopropylbenzoic acid from $p$-isopropyltoluene suggested that $p$-isopropylbenzyl alcohol and $p$-isopropylbenzaldehyde may be intermediates in a pathway analogous to that proposed by Dagley \& Patel (1957) for the oxidation of $p$-hydroxytoluene. To investigate this possibility the organism was examined for simultaneous induction of the capacity to oxidize $p$-isopropyltoluene and the suspected intermediates. Bacteria growing in the presence of glucose plus-p-isopropyltoluene exhibited a lag, corresponding to the exhaustion of glucose, after which growth was resumed (Fig. I). Organisms sampled before the lag did not oxidize $p$-isopropylbenzaldehyde, $p$-isopropylbenzyl alcohol or $p$-isopropyltoluene (Table $\mathrm{I}$ ). After the resumption of growth the organisms oxidized the three substrates, and the increase in the specific activities of the enzymes was accompanied by the accumulation of $p$-isopropylbenzoic acid in the culture medium (Table I). In addition, non-induced bacteria (time $2 \mathrm{hr}$ ) and induced bacteria (time $8 \mathrm{hr}$ ) were assayed manometrically for their ability to oxidize $p$-isopropyltoluene and the suspected aldehyde and alcohol derivatives (Fig. 2). These results indicate that the enzymes which were required for the oxidation of $p$-isopropyltoluene to $p$-isopropylbenzoic acid were simultaneously 


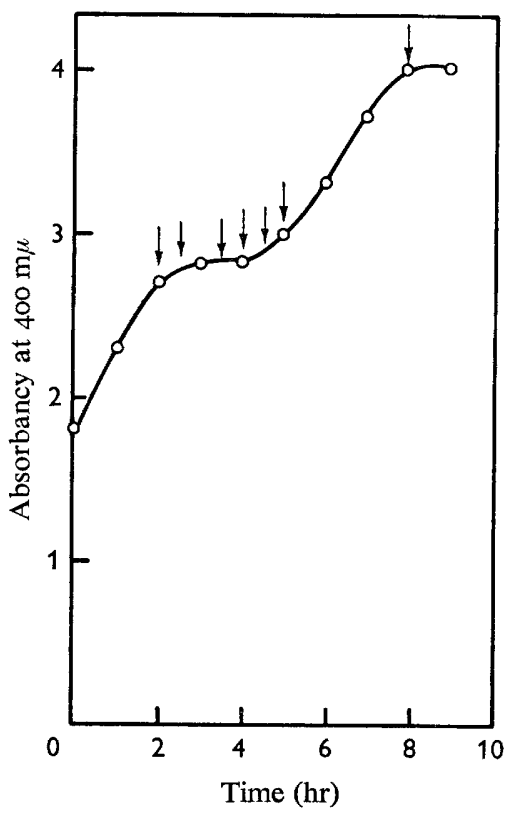

Fig. I

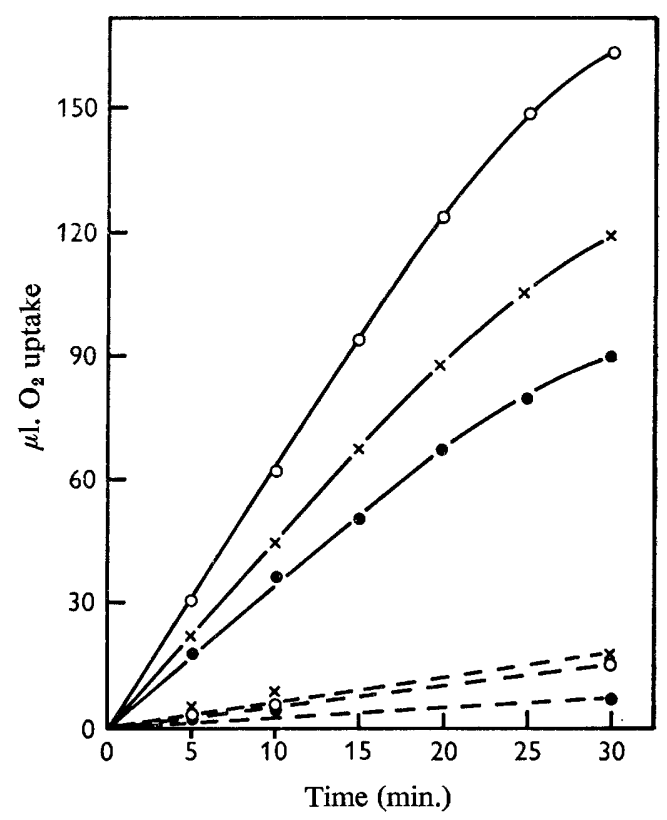

Fig. 2

Fig. I. Growth of Pseudomonas sp. on a medium containing glucose plus $p$-isopropyltoluene. Glucose ( $0 \cdot 1 \%)$ and $p$-isopropyltoluene $(0.1 \%)$ were added at zero time to a culture that had been grown for $\mathrm{I} 8 \mathrm{hr}$ in the presence of glucose $(0 . \mathrm{I} \%)$. After $3 \mathrm{hr}$ glucose was no longer detected in the medium. Samples $(0.5 \mathrm{ml}$.) were removed at the points marked with arrows (see Table I).

Fig. 2. Oxidation of $p$-isopropyltoluene (O), $p$-isopropylbenzyl alcohol $(\times)$ and $p$-isopropylbenzaldehyde $(O)$ by glucose-grown (--) and $p$-isopropyltoluene-grown $(-)$ bacteria. The organisms, both non-induced (time $2 \mathrm{hr}$, Table I) and induced (time $8 \mathrm{hr}$, Table I), were harvested and resuspended in distilled water. Oxygen uptake was measured manometrically in the presence of $20 \%(\mathrm{w} / \mathrm{v}) \mathrm{KOH}$; the incubation mixtures contained $(2 \cdot 0 \mathrm{ml}$. final volume): substrate, $33 \mu$ moles; phosphate buffer $\mathrm{pH} 8.0,100 \mu$ moles; organisms, $0.5 \mathrm{mg}$.; and distilled water.

\section{Table I. Induction of enzymic activities by p-isopropyltoluene}

Samples were removed during the incubation shown in Fig. I and tested for oxidative ability and $p$-isopropyl benzoic acid content. Reaction mixtures were as described in the Methods section.

\begin{tabular}{|c|c|c|c|c|}
\hline \multirow[b]{2}{*}{$\begin{array}{l}\text { Time } \\
\text { (hr) }\end{array}$} & \multicolumn{3}{|c|}{ Substrate oxidation ( $\mu$ mole $\times 100 / \mathrm{mg}$. organism $/ \mathrm{hr}$ ) } & \multirow{2}{*}{$\begin{array}{c}p \text {-Isopropylbenzoic } \\
\text { acid formed } \\
\text { ( } \mu \mathrm{g} . / \mathrm{mg} . \text { of } \\
\text { organisms) }\end{array}$} \\
\hline & $\begin{array}{l}p \text {-Isopropyl- } \\
\text { toluene }\end{array}$ & $\begin{array}{l}p \text {-Isopropyl- } \\
\text { benzyl alcohol }\end{array}$ & $\begin{array}{l}p \text {-Isopropyl- } \\
\text { benzaldehyde }\end{array}$ & \\
\hline 2.0 & 0.0 & 0.0 & 0.0 & 0 \\
\hline 2.5 & 0.0 & $2 I \cdot 0$ & I I 9 & 64 \\
\hline 3.5 & $8 \cdot I$ & $66 \cdot 5$ & $23 \cdot 8$ & 142 \\
\hline $4 \cdot 0$ & I $4 \cdot 3$ & $76 \cdot 5$ & $57 \cdot 2$ & I 56 \\
\hline 4.5 & $11 \cdot 9$ & $8 \mathrm{I}^{\circ} \mathrm{O}$ & 95.0 & 102 \\
\hline 5.0 & $8 \cdot 6$ & $67 \cdot 0$ & $66 \cdot 6$ & 49 \\
\hline 8.0 & $8 \cdot 6$ & $57^{\circ} 0$ & $62 \cdot 0$ & 44 \\
\hline
\end{tabular}


induced by $p$-isopropyltoluene or a product of its oxidation, and that the enzymes were also repressed by glucose.

Neither $p$-isopropylbenzaldehyde nor $p$-isopropylbenzyl alcohol were effective either as inducers or as growth substrates when added to a liquid culture of organisms grown with a limiting concentration of glucose. However $p$-isopropylbenzoate proved to be a utilizable carbon source and its effect on the induction of the three enzymes was examined (Table 2). Bacteria grown in the presence of $p$-isopropylbenzoic acid were capable of oxidizing the three suspected intermediates at a rate which was slightly in excess of that of bacteria grown on $p$-isopropyltoluene. This observation suggests that $p$-isopropylbenzoic acid or its oxidation product induced the formation of the enzymes for the three reactions examined.

Table 2. Oxidative capacities of p-isopropyltoluene-grown and p-isopropylbenzoate-grown organisms

Reaction mixtures were as described in the Methods section.

Substrate

p-Isopropyltoluene p-Isopropylbenzyl alcohol $p$-Isopropylbenzaldehyde
Oxidation of substrates ( $\mu$ mole $\times 100 / \mathrm{mg}$. organisms/hr) by organisms grown on

$\overbrace{\text {-Isopropyltoluene }}^{p \text {-Isopropylbenzoate }}$

$\begin{array}{rr}8.6 & 10.9 \\ 81.6 & \text { I } 14.0 \\ 43.5 & 50.0\end{array}$

Table 3. Ability of various aromatic compounds to function as either inducers or growth substances

Organisms were suspended to equal densities and assayed for their ability to oxidize $p$-isopropyltoluene as described in the Methods section.

Carbon source

p-Isopropyltoluene p-Isoprpyolbenzyl alcohol p-Isopropropylbenzaldehyde p-Isopropylcatechol

Toluene

Benzaldehyde

Benzene

$o$-Cresol

$m$-Cresol

p-Cresol

Catechol

Isopropylbenzene

Since both $p$-isopropylbenzaldehyde and $p$-isopropylbenzyl alcohol were apparently toxic when added directly to the mineral salts medium, their effectiveness as inducers was re-examined by using the mineral medium solidified by $2 \%(\mathrm{w} / \mathrm{v})$ agar as culture medium and with the aromatic derivative furnished in the vapour phase. Other related aromatic compounds were tested for their ability to function as carbon sources or inducers (Table 3 ). Of all the compounds assayed, only $p$-isopropyltoluene, $p$-iso- 
propylbenzaldehyde and $p$-isopropylbenzyl alcohol supported the growth of the organism and induced the formation of the enzymes necessary for the oxidation of $p$-isopropyltoluene.

\section{Studies with cell-free preparations}

The results with whole organisms suggested that the oxidation of $p$-isopropyltoluene proceeded by the oxidation of the methyl group via the alcohol to the aldehyde and then to the acid derivative. Additional evidence favouring this pathway was obtained with cell-free extracts prepared from glucose-grown and from $p$-isopropyltoluene-grown bacteria (Table 4). Extracts prepared from $p$-isopropyltoluenegrown bacteria oxidized $p$-isopropylbenzyl alcohol and $p$-isopropylbenzaldehyde but not $p$-isopropyltoluene. Extracts of glucose-grown organisms did not oxidize any of the substrates. The addition of NAD, NADP, or the reduced derivatives did not stimulate the oxidation of $p$-isopropyltoluene by either extract. Extracts prepared in the presence of $0.1 \mathrm{M}$ mercaptoethanol oxidized $p$-isopropyltoluene. The mercaptoethanol was equally effective when added after extraction and could be replaced by the addition of cysteine plus ethanol to the reaction mixture (Table 5). Under the same conditions, extracts prepared from glucose-grown cells were completely inactive.

Table 4. Oxidative capacities of extracts of glucose-grown and p-isopropyltoluene-grown bacteria

Reaction mixture was as described in the Methods section.

\begin{tabular}{|c|c|c|}
\hline \multirow[b]{2}{*}{ Substrate } & \multicolumn{2}{|c|}{$\begin{array}{c}\text { Oxidation of substrates } \\
(\mu \text { mole } \times 100 / \mathrm{mg} . \text { protein } / \mathrm{hr}) \\
\text { by extracts of } \\
\text { organisms grown on }\end{array}$} \\
\hline & Glucose & $\begin{array}{l}p \text {-Isopropyl- } \\
\text { toluene }\end{array}$ \\
\hline$p$-Isopropyltoluene & 0.00 & 0.00 \\
\hline$p$-Isopropylbenzyl alcohol & 0.00 & $6 I \cdot 0$ \\
\hline$p$-Isopropylbenzaldehyde & 0.00 & $178 \cdot 0$ \\
\hline
\end{tabular}

Table 5. The effect of cysteine and ethyl alcohol on the oxidation of p-isopropyltoluene by extracts of p-isopropyltoluene-grown and glucose-grown bacteria

Reaction mixture as described in the Methods section.

$\begin{array}{lcc}\quad \text { Glucose } & \begin{array}{c}\text { Oxidation of } p \text {-isopropyltoluene } \\ (\mu \text { mole } \times \text { I00/mg. protein/hr) by } \\ \text { extracts of organisms grown on } \\ \text { Additions }\end{array} & \begin{array}{c}p \text {-Isopropyl- } \\ \text { toluene }\end{array} \\ \text { None } & 0.00 & 0.00 \\ \text { Ethyl alcohol } & 0.00 & 0.95 \\ \text { Cysteine } & 0.00 & 3.8 \\ \text { Ethyl alcohol +cysteine } & 0.00 & 12.4\end{array}$

\section{p-Isopropylbenzoic acid formation}

After incubation for $3.5 \mathrm{hr}$ in the supplemented reaction mixture, the formation of $p$-isopropylbenzoic acid from $p$-isopropyltoluene by cell-free extracts could not be 
detected. However, after incubation for $\mathrm{I} 8 \mathrm{hr}$ an ultraviolet-absorbing acidic product was detected chromatographically. This acid was tentatively identified as $p$-isopropylbenzoic acid on the basis of its $R_{F}$ value in the two solvent systems cited (solvent $\mathrm{A}$, $\mathrm{R}_{F}$ value 0.66; solvent $\mathrm{B}, R_{F}$ value 0.96). A second acid was also detected chromatographically in the ethereal extract. It had a lower $R_{F}$ value (solvent $\mathrm{A}, R_{F}$ value 0.09) and did not absorb in the ultraviolet region when observed under a lamp emitting ultraviolet radiation at $253 \mathrm{~m} \mu$; this may represent a product of ring fission, but further identification has not been attempted. A supplemented reaction mixture containing boiled extract and substrate did not accumulate any detectable products. Because of the prolonged incubation period ( $18 \mathrm{hr}$ ) an additional control was used to eliminate the possibility that the reaction mixture had supported the growth of bacteria which were themselves responsible for the formation of $p$-isopropylbenzoic acid. A supplemented reaction mixture was incubated for $\mathrm{I} 8 \mathrm{hr}$ with $p$-isopropyltoluene. The mixture was then centrifuged for I $5 \mathrm{~min}$. at $34,000 \mathrm{~g}$ and the precipitated material resuspended in a solution containing tris buffer, ethanol, cysteine and $p$-isopropyltoluene. This mixture was incubated for $\mathrm{I} 8 \mathrm{hr}$ and then examined for $p$-isopropylbenzoic acid. No product was detected in this control reaction mixture. This observation substantiates the contention that despite the prolonged incubation period the formation of $p$-isopropylbenzoic acid from $p$-isopropyltoluene was catalyzed by the soluble extract.

When reaction mixtures, supplemented with NAD, and containing crude extract prepared from $p$-isopropyltoluene-grown bacteria were incubated with $p$-isopropylbenzyl alcohol or with $p$-isopropylbenzaldehyde for $3 \mathrm{hr}$ under $\mathrm{N}_{2}$. The formation of $p$-isopropylbenzoic acid was detected. Oxygen was excluded in order to eliminate autoxidation of the substrates and NAD was added because preliminary experiments indicated that this nucleotide cofactor was required for the oxidation of $p$-isopropylbenzaldehyde and of $p$-isopropylbenzyl aicohol. The acidic product was isolated from the reaction mixtures and identified chromatographically (solvent $\mathrm{A}, R_{F}$, value 0.66 ; solvent, B, $R_{F}$ value 0.96; column A, retention time of methyl ester 4.5 ; column $B$, retention time of methyl ester $4 \cdot I$ ). Reaction mixtures of boiled extract and either substrate did not contain any detectable reaction products after the period of incubation.

\section{DISCUSSION}

The pathway of $p$-isopropyltoluene degradation as suggested by these studies proceeds via the formation of $p$-isopropylbenzyl alcohol to $p$-isopropylbenzaldehyde and ultimately to $p$-isopropylbenzoic acid. By analogy to other aromatic systems (Evans, 1963) it is probable that $p$-isopropylbenzoic acid is hydroxylated before ring cleavage. Such products of ring hydroxylation are at the moment unknown, since they have not been shown to accumulate in the presence of either growing bacteria or cell-free extracts in the system studied.

The oxidation of $p$-isopropyltoluene by cell-free extracts is apparently dependent on the presence of both cysteine and ethanol although their precise role is at the present unknown. The possibility that the ethanol functions as a reductant for a cofactor appears unlikely, since neither reduced NAD nor NADP could be used to replace the alcohol. It is possible that the ethanol is in some way involved in the interaction between the water soluble enzyme and the water insoluble substrate. The whole organism pre- 
sumably has a mechanism for bringing such an interaction about; a mechanism which is destroyed when the organism is ruptured. This explanation is at the moment under investigation.

The toxicity of $p$-isopropylbenzaldehyde and $p$-isopropylbenzyle alcohol is presumed to be a reflexion of the level of the unoxidized intermediate when added to the liquid medium. Supplying the intermediate in the vapour phase reduces this level to a minimum and permits growth to occur. Presumably the same result could be achieved by the slow, continuous addition of the hydrocarbon to the liquid medium, keeping the compound below a toxic level.

The observation of diauxic growth exhibited by bacteria grown in the presence of glucose plus $p$-isopropyltoluene and the comparative enzyme studies involving extracts prepared from bacteria grown on the respective carbon sources illustrates repression, by glucose, of the enzymes involved in the degradation of $p$-isopropyltoluene. It appears that these enzymes, presumably $p$-isopropyltoluene oxidase, $p$-isopropylbenzyl alcohol dehydrogenase and $p$-isopropylbenzaldehyde dehydrogenase, are inducible; but the compound responsible for induction has not been established. The fact that bacteria grown on $p$-isopropylbenzoic acid contain the enzymes necessary for the degradation of $p$-isopropyltoluene would implicate the acid as either an inducer or a source of the inducer. Moreover, a comparison of the formation of the acid during the metabolism of $p$-isopropyltoluene with the appearance and increase in specific activities of the three enzymes would suggest that the acid in addition to the hydrocarbon induces the formation of the first three catabolic enzymes. The control of mandelate degradation, involving both repression and induction, bears some similarities to the control of $p$-isopropyltoluene degradation; Hegeman (1966) showed that benzoyl formate induced the formation of the three early enzymes in the mandelate pathway. However, by using mutants blocked in the early reactions, he also showed that the D- and L-isomers of mandelate were equipotent inducers. Whether or not $p$-isopropyltoluene is itself as potent an inducer as $p$-isopropylbenzoic acid of the corresponding pathway remains to be decided. The advantage of induction by an intermediate of the early enzymes in each respective pathway is perhaps more easily understood in light of the nature of the substrates in the $p$-isopropyltoluene pathway. Because the starting compound is water-insoluble, its concentration at the site of induction may never be high enough to elicit the maximal degree of enzyme formation. $p$-Isopropylbenzoic acid, as its salt, does not suffer from this limitation and so an organism with an inductive apparatus capable of responding to the acid would have a selective advantage over one deficient in that ability. An extension of this explanation to include the mandelate and other pathways which are susceptible to such a control mechanism would then be a matter of evolution, proceeding naturally from the highly reduced hydrocarbon to the more oxidized substrates as carbon sources, but maintaining the initial, once selective, advantage of 'back induction'.

I am grateful to Mr F. X. Ryan for his excellent technical assistance. 


\section{REFERENCES}

BERGMEYER, H. U. \& BERNT, E. (1963). Glucose determination with glucose oxidase and peroxidase. Meth. enzymat. Analysis, p. I23.

Dagley, S. \& Patel, M. D. (I957). Oxidation of $p$-cresol and related compounds by a Pseudomonas. Biochem. J. 66, 227.

Davis, J. B. \& RAYMOND, R. L. (1961). Oxidation of alkyl-substituted cyclic hydrocarbons by a Nocardia during growth on $n$-alkanes. Appl. Microbiol. 9, 383.

Evans, W. C. (1963). The microbiological degradation of aromatic compounds. J. gen. Microbiol. 32, 177 .

Hegeman, G. D. (1966). Synthesis of the enzymes of the mandelate pathway by Pseudomonas putida. II. Isolation and properties of blocked mutants. J. Bact. 9r, I I 55 .

ITZHAKI, R. \& GILL, D. M. (1964). A micro-biuret method for estimating proteins. Analyt. Biochem. 9, $40 \mathrm{I}$.

Yamada, K., Horiguchi, S. \& TAKahashi, J. (1965). Studies on the utilization of hydrocarbons by microorganisms. VI. Screening of aromatic hydrocarbon-assimilating microorganisms and cumic acid formation from p-cymene. Agric. biol. Chem. 29, 943. 